\section{Visión Electrónica Más que un estado sólido \\ https://doi.org/10.14483/issn.2248-4728}

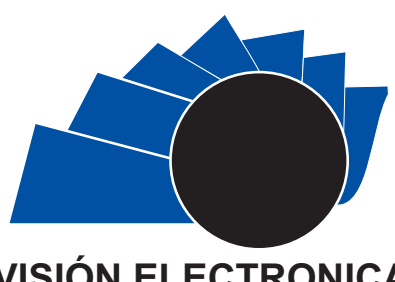

VISIÓN ELECTRONICA

UNIVERSIDAD DISTRITAL

FRANCISCO JOSÉ DE CALDAS

A Case-Study Vision

\title{
Development of a GFDM waveform with radio defined with software
}

\author{
Desarrollo de una forma de onda GFDM con radio definida por software
}

\author{
Daniel Ricardo Pérez-Riaño ${ }^{1}$ Elkin Andrés Ducuara-Hernández ${ }^{2}$, \\ Luis Fernando Pedraza-Martínez ${ }^{3}$
}

\section{INFORMACIÓN DEL ARTICULO}

Historia del articulo

Enviado: 05/10/2018

Recibido: 21/10/2018

Aceptado: 10/11/2018

\section{Keywords:}

GFDM,

OFDM,

Out of Band radiation,

SDR,

Spectral efficiency,

Waveform.

\section{Palabras clave:}

GFDM,

OFDM,

Out of Band radiation,

SDR,

Spectral efficiency,

Waveform.

\section{ABSTRACT}

In this paper the performance of a Generalized Frequency Division Multiplexing waveform is evaluated when compared to an Orthogonal Frequency Division Multiplexing signal. For the development of the previous waveforms, the GNU radio software and the Software Defined Radio (SDR) equipment USRP N210 are used. Through a spectrum analyzer the power of both waveforms are measured and the Out-of-Band Radiation is analyzed. Then, the results obtained are compared and the advantages and disadvantages of the implementation of GFDM as a waveform within the fifth generation systems are exposed.

\section{RESUMEN:}

En este documento se evalúa el desempeño de una forma de onda GFDM (Generalized Frequency Division Multiplexing) que es comparada con una señal OFDM (Orthogonal Frequency Division Multiplexing). Para el desarrollo de las anteriores formas de onda se utilizan el software GNU radio y los equipos de Radio Definida por Software (SDR) USRP N2 10. Mediante un analizador de espectros se mide la potencia de ambas formas de onda y se analiza la Radiación Fuera de Banda (OOB). Luego, se comparan los resultados obtenidos y se exponen las ventajas e inconvenientes de la implementación de GFDM como forma de onda dentro de los sistemas de quinta generación.

${ }^{1}$ BSc. In Telecommunications Engineering, Universidad Distrital Francisco José de Caldas, Bogotá, Colombia. Current position: ZTE Corporation, Bogotá, Colombia. E-mail darperezr@,correo.udistrital.edu.co.ORCID: https://orcid.org/0000-0002-6172-952X.

${ }^{2}$ BSc. In Telecommunications Engineering, Universidad Distrital Francisco José de Caldas, Bogotá, Colombia. Current position: Huawei Technologies, Bogotá, Colombia. E-mail: eaducuarah@,correo.udistrital.edu.co ORCID: https://orcid.org/0000-0001-5484-4805.

${ }^{3}$ BSc. In Electronic Engineering, MSc. In Teleinformatics, Universidad Distrital Francisco José de Caldas, Bogotá, Colombia. Ph.D. In Computation and Systems Engineering, Universidad Nacional de Colombia, Bogotá, Colombia. Current position: Professor at Universidad Distrital Francisco José de Caldas, Bogotá, Colombia. E-mail: lfpedrazam@udistrital.edu.co. ORCID: https://orcid.org/0000-0002-0997-6478.

Cite this article as: D. R. Pérez-Riaño, E. A. Ducuara-Hernández and L. F. Pedraza-Martínez, "Development of a GFDM waveform with radio defined with software", Visión electrónica, algo más que un estado sólido, vol. 1, no. 2, Special edition, july-december 2018. DOI revista: https://doi.org/10.14483/issn.2248-4728 


\section{Introduction}

Currently the communications systems are in an evolution stage towards the fifth generation networks $(5 \mathrm{G})[1]$; this is because of the quantity of users and mobile devices are in constant growth. Besides some of the new applications and services raised by IoT (Internet of Things) [2-3] demand that the communications are transformed at URLLC (Ultra-Reliable Low-Latency Communications) systems [4-5], providing shorter time responses that the offered by $4 G$ networks nowadays [6]. It's for this reason that it is make fundamental to choose a waveform that offer high performance in terms of spectral efficiency (SE), latency, transmission rate and energy consumption in order to achieve the implementation of next generation systems, [7].

OFDM is the waveform employed for the $4 \mathrm{G}$ today because it provides transmission rates that cover adequately the requirements raised by the services rendered in this generation [8], without use an excessive computational complexity [7]. Likewise, it has been widely used in digital television and different technologies like WIMAX, WIFI, and LTE among other [9-12]. However, OFDM has many problems that do not allow it to be a waveform candidate for the $5 \mathrm{G}$ systems, [8]. One of them is that it owns a high PAPR (Peak to Average Power Ratio) that results in inefficient power use, as well as out of band emissions that do not allow to achieve an optimum spectrum use.

For the above, to use in a better way the radioelectric spectrum one of the proposals it's to implement GFDM on the $5 \mathrm{G}$ networks [13] which differs from OFDM because it doesn't consist in an orthogonal carriers system but it is based in a block multi-carrier scheme [14] that allows to transmit several symbols for each sub-carrier achieving thus increase the transmission rate.

Equally, OFDM allow to improve the spectral efficiency, reduce the $\mathrm{PAPR}$, decrease the $\mathrm{OoB}$ radiation and belittle BER (Bit Error Rate) [15], since it utilized a RRC (Root Raised Cosine) or RC (Raised Cosine) filter in each sub-carrier [14]. Also GFDM gathers characteristics that would allow it to be compatible with technologies of spectrum dynamic access as cognitive radio [16].

In consequence, the implementation of these communication systems require to use specialized and expensive equipment. However, thanks to SDR is possible made and test the different wave types and technologies using the same hardware, and it has become in an excellent alternative due to its versatility [17-18]. Which has allowed it to perform tests in FM, DVB-T, WLAN, GSM, and LTE, among others [1922].

As indicated above, the applications that have been made using software-defined radio equipment consist of the implementation of proposals for the next generation of digital terrestrial television systems ISDB-TB using the FBMC modulation (Filter Bank Multi-Carrier) [23]; In addition, some models have been designed to improve existing modulation schemes, such as the validation of 16-CQAM (Cantor Quadrature Amplitude Modulation) with SDR [24]; it has also been possible to implement spectrum access efficiently using cognitive radio networks [25-26]; and even tests have been made with arrangements of intelligent antennas to direct the radiation pattern towards a specific point or a signal of interest(SOI), [27].

The structure of this article is as follows: First, it is explained the GFDM including OoB radiation meaning and they are exposed some proposals to solve the $\mathrm{OoB}$ emissions problem; later the materials are described, elements and equipment employed to generate the waveforms as well as the instrumentation that it has been taken in measuring of the data that was analyzed; Then, it is described the process to test GFDM an OFDM systems; After, it is explained and discussed the results obtained; and finally the conclusions are exposed.

\section{Out of Band radiation and GFDM}

A large number of multi-carrier schemes have been proposed to replace OFDM, which is the waveform used by various communication systems today. [28-29], because this is affected by phenomena such as the high ratio of PAPR [30] that introduces very high power hops with respect to the average power value that the system can deliver, causing degradation in the performance of the transmitter when the signal passes through a non-linear power amplifier [31]. Although in the domain of the OFDM frequency it shows a uniform spectrum of power, observing its waveform in the time domain gives an unstable signal [32].

Although PAPR is a major problem in OFDM, Out-ofBand emissions become the most marked problem presented in this modulation scheme, and this reason turns out to be one of the greatest challenges in the implementation of the new generation systems. 


\subsection{Out of Band Emissions (OOBE)}

The phenomenon of Out-of-Band radiation is generated within systems that employ OFDM [33], because components such as power amplifiers distort the signal causing unwanted radiation that results in the creation of side lobes at the ends of the assigned band.

Therefore, to mitigate this phenomenon, various techniques have been used that aim to reduce interference on adjacent bands, [34]. One of them is the use of guard spaces on both sides of the transmission channel in order to attenuate the radiation on neighboring channels. Although this methodology greatly reduces OOBE in the adjacent bands, it reduces the spectral efficiency considerably since in these guard bands no information is sent and for this reason this spectrum is wasted. In the case of LTE systems, it is estimated that the value of the guard interval is $10 \%$ of the bandwidth assigned to the transmission channel [35-36].

On the other side, the carrier cancellation technique allows to reduce the side lobes product of unwanted emissions in the adjacent bands by using a specific number of carriers to transmit, and assign the unused ones to the end of the transmission channel and in this way reduce radiation in adjacent bands [34]. This type of methods has been modeled for WiMAX technology and MIMO-OFDM systems (Multiple Input - Multiple Output) [37], but its implementation decreases the SE.

Likewise, another of the proposed schemes to solve the problem of OOB radiation is to apply a spectral conformation filter in the time domain. One of the advantages of this technique is that the spectral efficiency may increase depending on its implementation, but it results in an increase in the PAPR [34] which is another of the great disadvantages of OFDM and has been explained previously.

On the one hand, the use of analog filtering, in combination with digital pre-distortion in the frequency domain, reduces OoB radiation within MultiUser MIMO systems (MU-MIMO) but degrades the signal to interference, noise and distortion (SINDR), which results in a considerable deterioration in the BER, [38].

\subsection{Model of a GFDM system}

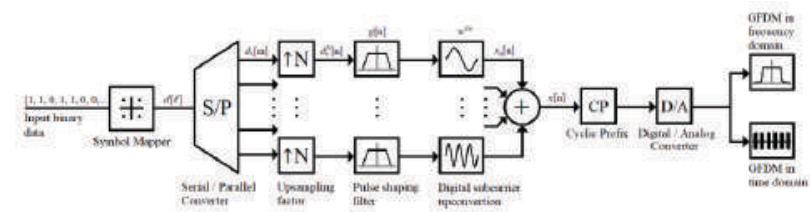

Figure 1. Model of a GFDM system. Source: own, based in [41].
On the other hand, GFDM is based on the modulation of independent blocks, where each block contains a number of subcarriers and sub-symbols. To achieve the transmission of information using this type of systems, the process described in Figure 1 is performed.

Initially, information data are available in binary form; these are modulated in QAM (Quadrature Amplitude Modulation) to obtain the symbols that can be mapped in a constellation diagram. The resulting symbols are expressed in a complex way; in Figure 1, the symbol flow is denoted by $d[\ell]$, where $\ell=0,1,2,3 \ldots$ $K$ - 1. Where $d[\ell] \in \mathbb{C}$ and $K$ is the number of subcarriers that transmit information (active subcarriers). The resulting flow of symbols passes through a Series - Parallel converter. As a result of this process we have a matrix, expressed in (1).

$$
d_{k}[m]=\left[\begin{array}{ccc}
d_{0}[0] & \cdots & d_{0}[M-1] \\
\vdots & \ddots & \vdots \\
d_{K-1}[0] & \cdots & d_{K-1}[K-1]
\end{array}\right]
$$

Here, $M$ is the number of sub-symbols and $K$ is the number of sub-carriers. After, the symbols of each subcarrier enter to an up-sampling process [39], to get the sequence that show the equation (2).

$$
d_{k}^{N}[n]=\sum_{m=0}^{M-1} d_{k}[m] \delta[n-m N]
$$

In (2) it can be seen that the Dirac delta function is applied to the symbols of each subcarrier $(\delta[])[40]$, responsible for raising the sampling rate $N$ times, obtaining in this way a plot of length $M N$ in the $k$-th sub-carrier, [41]. Subsequently a pulse shaping filter is used for each of the sequences obtained after increasing the sampling; the objective of these filters is to minimize Out-of-Band emissions in the resulting waveform at the output of the GFDM system [42]; the pulse shaping filter is a sequence of size $n$ just like the frame that contains the data information, [43]. To apply the filter to each of the data sequences, circular convolution is used, as illustrated in (3).

$$
\left(d_{k}^{N} \circledast g\right)[n]
$$

The data obtained in this stage is made a frequency shift by applying a digital subcarrier converter, denoted in figure 1 as $w^{k n}=e^{j \frac{2 \pi}{N} k n}$ So that each GFDM subcarrier signal is spaced in the frequency domain; the equation (4) describes each of these subcarriers: 


$$
x_{k}[n]=\left(d_{k}^{N} \circledast g\right)[n] * w^{k n}
$$

In order to obtain the GFDM waveform to be transmitted, all the signals generated from the digital subcarrier converters are added, as shown in (5).

$$
x[n]=\sum_{k=0}^{K-1} x_{k}[n]
$$

After obtaining the GFDM waveform, a cyclic prefix $(\mathrm{CP})$ is added for each modulated block - instead of in each symbol as in OFDM - with the objective of minimizing inter-symbol interferences (ISI) and making the system, [44]. Finally, the modulated signal is passed through a Digital-Analog converter in order to be transmitted through the physical layer of the system used.

\section{Materials and methods}

To implement the systems and perform the measurements to be evaluated, laboratory equipment is required both to generate the waveforms that are being studied and the instrumentation that helps to capture the data that will be analyzed. Next, the methodology and resources used in the present investigation are mentioned.

As a matter of fact, the structure of the elements that are used to generate the OFDM and GFDM waveforms in order to perform the pertinent measurements to be evaluated are shown in Figure 2.
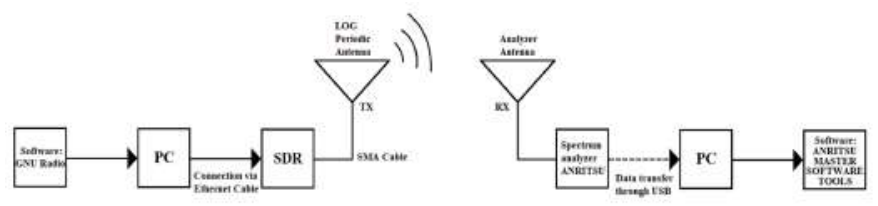

Figure 2. Block structure for measurements of the OFDM and GFDM waveforms. Source: own.

In Figure 2, it can be seen that the parameters to adjust to be able to model the signals to be transmitted originate from the programming made in "GNU Radio" - whose program description is found in Table 1; To be able to perform the proper programming using GFDM, external libraries must be used that are downloaded independently [45]. GNU Radio uses the resources of a computer to establish a connection with SoftwareDefined Radio equipment through the Ethernet ports (the Gigabit-Ethernet standard is more specifically used because the radio equipment handles this standard); through the radio device the transmission of the signal generated using a Periodic Log antenna is made.

However, the waveform transmitted by the SDR equipment is received by the spectrum analyzer which, during a time interval, will record the received power values in a previously adjusted frequency range, allowing to observe in detail both the waveform that is commissioned of transmitting the data as the Out-ofBand radiation that is generated in terms of the type of modulation used. This data is stored and transported to a computer through a USB memory to be analyzed in detail in the "Anritsu Master Software Tools" program, described in Table 1.

\subsection{Software Defined Radio (SDR)}

The operation of these equipment consists of carrying out the signal processing through a computer program to then make use of the hardware present in these devices, in this way it allows generating the waveforms that it is desired to transmit and in addition it can be capable of demodulating the information received [17]. A specific example of Software-Defined Radio is the USRP (Universal Software Radio Peripheral) designed by the company Ettus Research, the USRP N210 devices are the ones used in the present work to adequately generate the OFDM and GFDM waveforms.

\subsection{Elements used}

The elements used are shown in Table 1, it illustrates the OFDM and GFDM systems studied and implemented in this work, in order to be developed in an appropriate manner.

Figure 3, illustrates the arrangement of the equipment that was used to generate the OFDM and GFDM signals using all the elements described in Table 1 , in addition to taking into account the structure described in the blocks of Figure 2.

\begin{tabular}{|l|l|}
\hline ELEMENT & DESCRIPTION \\
\hline $\begin{array}{l}\text { Antenas } \\
\text { LP410: }\end{array}$ & $\begin{array}{l}\text { Log Periodic antenna that operate in a frequency range of } 400 \mathrm{MHz} \text { to } 1 \mathrm{GHz} \\
\text { and gain of } 5-6 \mathrm{dBi},[46] .\end{array}$ \\
\hline $\begin{array}{l}\text { USRP } \\
\text { N210: }\end{array}$ & $\begin{array}{l}\text { This equipment allows to process signals with frequency ranging from DC to } \\
6 \mathrm{GHz}, \text { has expansion ports for additional cards and ports to synchronize with } \\
\text { multiple USRPs, [46]. }\end{array}$ \\
\hline $\begin{array}{l}\text { Cable SMA- } \\
\text { SMA } \\
\text { [47]: }\end{array}$ & $\begin{array}{l}\text { It allows to connect the Periodic Log antenna with the USRP equipment, it has } \\
\text { minimum losses up to a frequency of } 6 \mathrm{GHz},[46] .\end{array}$ \\
\hline $\begin{array}{l}\text { Anritsu } \\
\text { MS2721B: }\end{array}$ & $\begin{array}{l}\text { Spectrum analyzer that operates up to a frequency of } 7.1 \mathrm{GHz} \text {, ideal for } \\
\text { spectrum analysis of wireless digital signals such as mobile networks and } \\
\text { digital video signal testing, [48]. }\end{array}$ \\
\hline $\begin{array}{l}\text { Anritsu } \\
\text { Master } \\
\text { Software } \\
\text { Tools: }\end{array}$ & $\begin{array}{l}\text { Program that allows to see in detail the data caught in the Anritsu spectrum } \\
\text { analyzer, it can also illustrate measurements in the frequency domain and see } \\
\text { the spectrogram taken in a range of frequencies during a certain interval of } \\
\text { time, [48]. }\end{array}$ \\
\hline
\end{tabular}

Table . Materials and tools utilized. Source: own. 


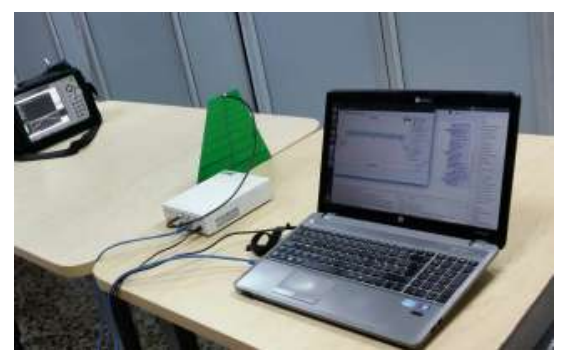

Figure 3. Arrangement of laboratory equipment to perform the measurements of the evaluated waveforms. Source: own.

To perform the behavior analysis in each of the waveforms to be studied (GFDM and OFDM), the initial parameters are adjusted according to Table 2 .

\begin{tabular}{|l|l|l|}
\hline PARAMETER & GFDM & OFDM \\
\hline FFT length & 128 & 128 \\
\hline Active Sub-Carriers (\#) & 110 & 110 \\
\hline Number of Sub-Symbols $(\#)$ & 9 & 1 \\
\hline Cyclic Prefix length (CP) & 64 & 32 \\
\hline Cyclic Suffix length (CS) & 16 & N/A \\
\hline Frequency (MHz) & 670 & 670 \\
\hline Total Band (MHz) & $654.655-675.378$ & $654.655-675.378$ \\
\hline Band Width (MHz) & 10.723 & 10.723 \\
\hline Antenna Gain (dBi) & 5 & 5 \\
\hline
\end{tabular}

Table 2. Initial Parameters. Source: own.

\section{Results}

In this chapter, it is analyzed the data that was obtained from the measurements made to each of the waveforms taking into account that OFDM and GFDM must be comparable according to the initial parameters seen in the Table 2.

In addition, Figure 4 shows the result of the measurement taken, corresponding to the spectral representation of an OFDM signal; the data taken includes a range of frequencies ranging from 653.5 $\mathrm{MHz}$ to $686.5 \mathrm{MHz}$, you can see the power levels in both the frequency domain and a spectrogram.

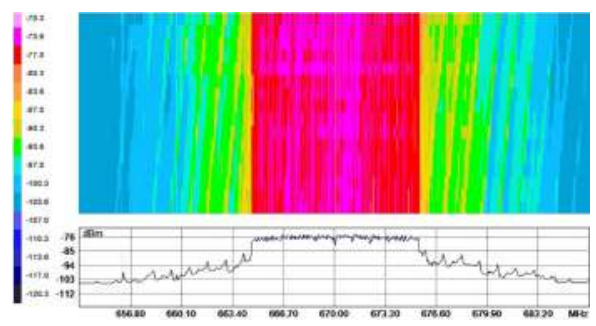

Figure 4. OFDM Spectrogram. Source: own.
At the same way, the representation for GFDM is illustrated in Figure 5.

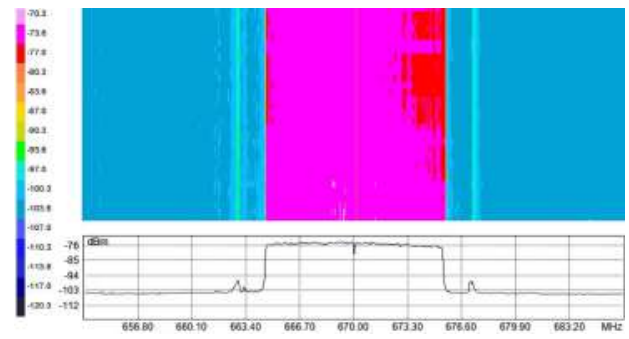

Figure 5. GFDM spectrogram. Source: own.

In systems that transmit multiple carriers the OOBE starts at the ends of the necessary band $\left(B_{N}\right)$ and it extends up to $250 \%$ of the bandwidth necessary to carry out the transmission in both limits of $B_{N}$, as shown in Figure 6. The radiations that are found after $250 \%$ of $B_{N}$ they are known as spurious emissions, [50].

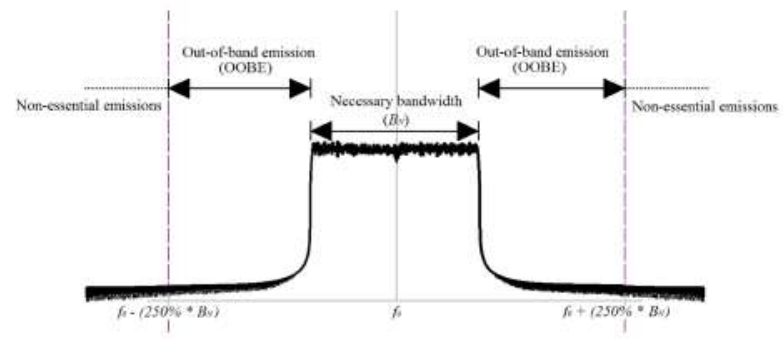

Figure 6. Out-of-Band radiation domain of $250 \%$ (2.5 times the necessary bandwidth) and non-essential emissions (general meaning). Source: own.

However, according to [51] a transmission in which the central frequency $\left(F_{0}\right)$ is in the frequency range of 30 $\mathrm{MHZ}<F_{0}<1 \mathrm{GHz}$ and in which the $\mathrm{B}_{\mathrm{N}}$ is greater than 10 $\mathrm{MHz}$, OOBE is extend until $1,5 \mathrm{~B}_{\mathrm{N}}+10 \mathrm{MHz}$, as indicated in Figure 7 .

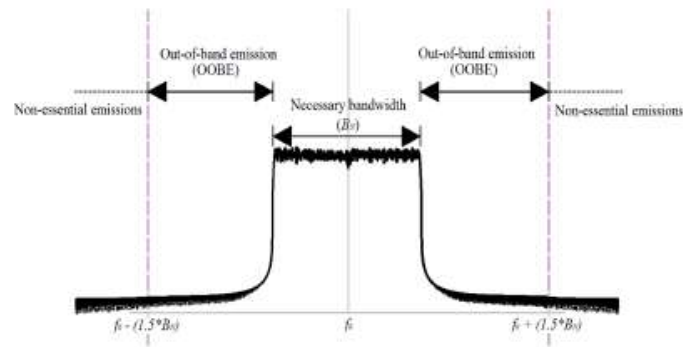

Figure 7. Out-of-Band radiation domain and nonessential emissions with " $30 \mathrm{MHZ}<f_{0<} 1 \mathrm{GHz}$ ” y " $\mathrm{B}_{\mathrm{N}}>10 \mathrm{MHz}$. Source: own. 
Once the power values are obtained, they are converted to units of power spectral density (PSD) using (6), in order to perform the respective analysis.

$$
\left.\operatorname{PSD}_{(d B m} / H_{z}\right)=\mathrm{P}_{d B m}-10 \log \left(\mathrm{BW}_{H z}\right)
$$

Then, a comparison between GFDM and OFDM is made in terms of the power spectral density as shown in Figure 8.

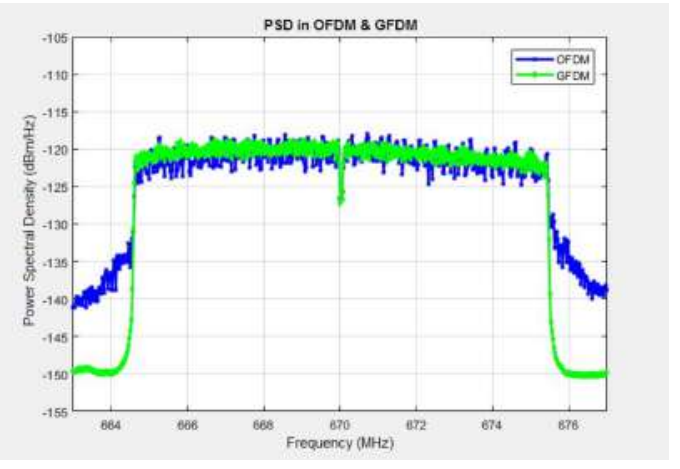

Figure 8. Comparison of the Power Spectral Density between a GFDM and OFDM signal. Source: own.

Figure 8, shows that the GFDM signal concentrates almost all of the power within the necessary bandwidth for transmission. In contrast, lateral lobes are generated in OFDM at both ends of the bandwidth necessary for transmission.

\subsection{Case 1}

To compare the results obtained, the first case compares the Out-of-Band radiation between GFDM and OFDM, assuming that a guard band of $10 \%$ is used, as stipulated in [35] and taking into account that the bandwidth allocated for the transmission is 10,723 $\mathrm{MHz}$, the Figure 9 shows the results of the comparison.

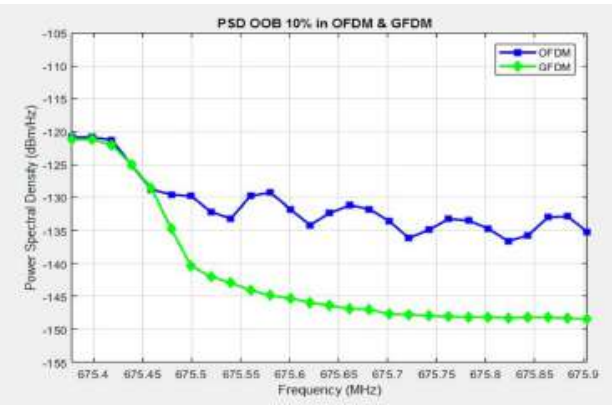

Figure 9. PSD comparison for $10 \%$ of the Out-ofBand domain between GFDM and OFDM.Source: own.
Table 3, shows the results obtained for power and spectral power density for OFDM and GFDM.

\begin{tabular}{|c|c|c|}
\hline PARAMETER & GFDM & OFDM \\
\hline Edge Sub-Carrier power (dBm) & $\begin{array}{l}- \\
76,4093332\end{array}$ & $\begin{array}{l}- \\
76,0746085\end{array}$ \\
\hline OOB power $10 \%(\mathrm{dBm})$ & $-103,66703$ & $\begin{array}{l}- \\
90,4387824\end{array}$ \\
\hline PSD OOB $10 \%(\mathrm{dBm} / \mathrm{Hz})$ & $\begin{array}{l}- \\
121,180546\end{array}$ & $\begin{array}{l}- \\
120,845821\end{array}$ \\
\hline PSD edge Sub-Carrier (dBm/Hz) & $\begin{array}{l}- \\
148,438243\end{array}$ & $\begin{array}{l} \\
135,209995\end{array}$ \\
\hline
\end{tabular}

Table 3. Power and PSD results in 10\% of the Outof-Band domain. Source: own.

When performing the analysis of the results shown in Table 3, it is possible to say that GFDM presents a reduction of $27.25 \mathrm{dBm} / \mathrm{Hz}$ with respect to the PSD in the last Sub-Carrier, while in OFDM there is a reduction of only $14.36 \mathrm{dBm} / \mathrm{Hz}$.

\subsection{Case 2}

In the second case, both waveforms are compared to determine the bandwidth of the OOB emission, taking in consideration that a noise floor is $-104 \mathrm{dBm}$.

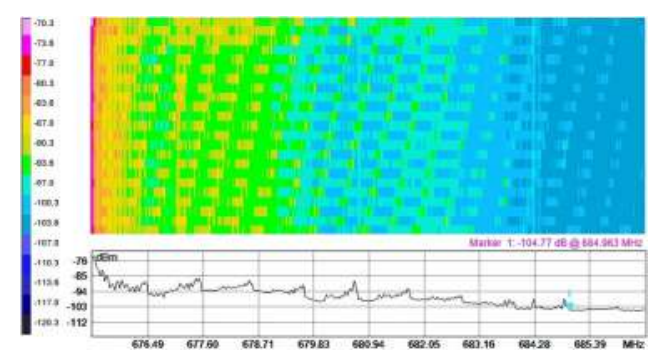

Figure 10. Out-of-Band spectrum in OFDM. Source: own.

Figure 10, shows the extent to which the out of band domain of an OFDM signal arrives, evidencing that it reaches a frequency of $684.963 \mathrm{MHz}$. Taking into account that the extreme frequency of the assigned band is $675.378 \mathrm{MHz}$, it can be deduced that the OOBE in OFDM occupies a bandwidth of $9.58 \mathrm{MHz}$, the Figure 11 shows the GFDM OOB.

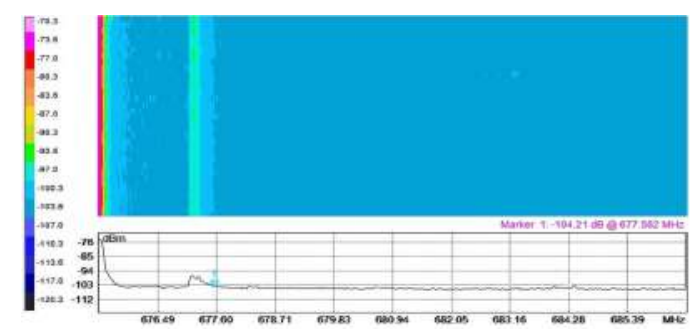

Figure 11. Out-of-Band spectrum in GFDM. Source: own. 
According to Figure 11, it can be said that the Out-ofBand domain of a GFDM signal has a value of 2.18 $\mathrm{MHz}$, which indicates a reduction of about a quarter of the bandwidth domain with respect to the OFDM signal.

\subsection{Case 3}

The amount of power spectral density that concentrates GFDM with respect to OFDM is analyzed. Another point is that Figure 12 presents the percentage of PSD that manages to concentrate GFDM and OFDM within the necessary bandwidth.

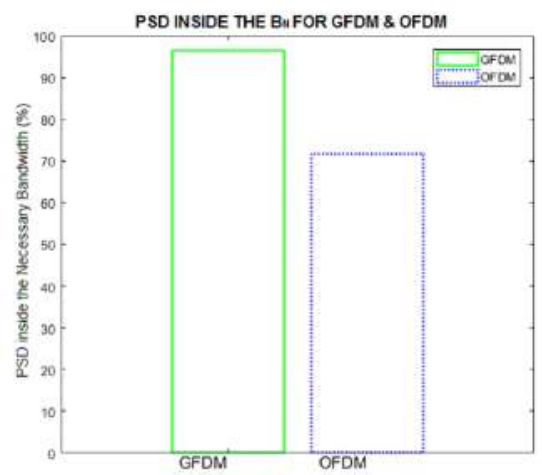

Figure 12. Concentrated PSD percentage within the bandwidth required for a GFDM and OFDM signal.

Source: own.

As it can be seen in Figure 12, GFDM manages to concentrate $96.46 \%$ of its PSD within the width of

\section{Conclusions}

Based on the results obtained, it is possible to say that GFDM can perfectly become the waveform used by $5 \mathrm{G}$ systems, because it is capable of concentrating $24.72 \%$ more of the PSD within the bandwidth of the frequency necessary to transmit the information in relation to OFDM. In addition, it manages to reduce emissions in the Out-of-Band domain with respect to OFDM by $77.24 \%$. For this reason, in the future the use of guard bands in wireless communication systems can be considerably reduced, thus increasing the spectral efficiency.

Thanks to the GFDM waveform allows the reduction of Out-of-Band radiation, it is possible to transmit more information through a channel adding more subcarriers, therefore GFDM would also allow a reassignment of frequencies where the bands used commercially are closer one of the another minimizing interference problem.

\section{Acknowledgements}

The development of this article has been possible thanks to the research group GIDENUTAS that has helped with the facility of the laboratory, the equipment used and the adequate physical rooms to carry out this research work.

\section{References}

[1] A. Gupta and R. K. Jha, "A Survey of $5 \mathrm{G}$ Network: Architecture and Emerging Technologies", IEEE Access, vol. 3, 2015, pp. $\begin{array}{lllllllll}1 & 2 & 0 & 6 & - & 1 & 2 & 3 & 2\end{array}$. https://doi.org/10.1109/ACCESS.2015.2461 602 .

A. Al-Fuqaha, M. Guizani, M. Mohammadi, M. Aledhari and M. Ayyash, "Internet of Things: A Survey on Enabling Technologies, Protocols, and Applications", IEEE Comunications surveys and tutorials, vol. 17, no. 4,2015, p p. $2347-2376$. https://doi.org/10.1109/COMST.2015.2444 095.

[3] G. A. Akpakwu, B. J. Silva, G. P. Hancke and A. M. Abu-Mahfouz, "A Survey on 5G Networks for the Internet of Things: Communication Technologies and Challenges", IEEE Access, vol. 6, 2018, pp. $\begin{array}{llllllllll}3 & 6 & 1 & 9 & - & 3 & 6 & 4 & 7\end{array}$. https://doi.org/10.1109/ACCESS.2017.2779 844.

[4] A. Mukherjee, "Energy Efficiency and Delay in 5G Ultra-Reliable Low-Latency Communications System Architectures", IEEE network, vol. 32, no. 2, 2018, pp. 55-61. https://doi.org/10.1109/MNET.2018.17002 $\underline{60 .}$.

[5] S. Eldessoki, D. Wieruch and B. Holfeld, "Impact of Waveforms on Coexistence of Mixed Numerologies in 5G URLLC Networks", WSA 2017; 21th International ITG Workshop on Smart Antennas, Berlin, Germany, 2017, pp.1-6. 
[6] Y. Li and G. Cheng, "Fourth generation wireless communication network", 3rd International Conference on Consumer Electronics, Communications and Networks, $2013, \quad \mathrm{p} \mathrm{p} . \quad 312-315$. https://doi.org/10.1109/CECNet.2013.6703 334.

[7] H. K. Bizaki, "Towards 5G Wireless Networks - A Physical Layer Perspective”, 2016. https://doi.org/10.5772/63098.

[8] N. Rani and S. Rani, "UFMC: The $5 \mathrm{G}$ modulation Technique”, IEEE international Conference on Computational Intelligence and computing Research, 2016, pp. 1-3. https://doi.org/10.1109/ICCIC.2016.7919 $\underline{714}$.

[9] S. Ajey, B. Srivalli and G. V. Rangaraj, "On performance of MIMO-OFDM based LTE systems", International Conference on Wireless Communication and Sensor Computing (ICWCSC), 2010 , pp. 1-5. https://doi.org/10.1109/ICWCSC.2010.54 $\underline{15899}$.

[10] L. Nasraoui, L. N. Atallah and M. Siala, "Reduced-Complexity synchronization technique for MIMO-OFDM WLAN systems", 5th International Conference on Communications and Networking ( C O M N T ), 2015 , p p. $1-5$. https://doi.org/10.1109/COMNET.2015.7 $\underline{566635}$.

[11] A. Sato, T. Shitomi, T. Takeuchi, M. Okano and K. Tsuchida, "Transmission performance evaluation of LDPC coded OFDM over actual propagation channels in urban area. Examination for next-generation ISDB-T", IEEE International Symposium on Broadband Multimedia Systems and Broadcasting (BMSB), 2017, pp. 1-5. https://doi.org/10.1109/BMSB.2017.7986 $\underline{224}$.

[12] S. G. Pasha and V. V. Kohir, "OFDM based
DVB-T system implementation using MATLAB and HDL coder", International Conference on Computing Methodologies and Communication (ICCMC), 2017, pp. $\begin{array}{llllllll}2 & 5 & 6 & - & 2 & 6 & 1\end{array}$. https://doi.org/10.1109/ICCMC.2017.828 $\underline{2686}$.

[13] G. Fettweis, M. Krondorf and S. Bittner, "GFDM - Generalized Frequency Division Multiplexing”, VTC Spring 2009 - IEEE 69th Vehicular Technology Conference, B a r c e 1 o n a, 2009, p p . $1-4$. https://doi.org/10.1109/VETECS.2009.50 $\underline{73571}$.

[14] L. Flores and L. Toscano, "Sistema de transmisión multiportadora mediante multiplexación por división de frecuencia generalizado (GFDM)", thesis, Universidad Politécnica Salesiana sede Quito, Quito, Ecuador, 2018, pp. 1-48.

[15] D. Gaspar, L. Mendes and T. Pimenta, "GFDM BER Under Synchronization Errors”, IEEE Communications Letters, vol. 21, no. 8, 2017, pp. $1743-1746$.

https://doi.org/10.1109/LCOMM.2017.26 $\underline{94837}$.

[16] N. A. Al-Hasaani, M. Namdar and H. Ilhan, "Energy detection of spectrum sensing for cognitive radio networks using GFDM modulation", 10th International Conference on Electrical and Electronics Engineering (ELECO), Bursa, 2017, pp. 690-694.

[17] V. I. Rodríguez, "Performance analysis of a fourth generation wireless comunication systems developed on a software defined radio enviroment", thesis Ph.D., Centro de Investigación Científica y de Educación Superior de Ensenada, Baja California, México, 2016. 
[18] D. Nguyen, "Implementation of OFDM systems using GNU Radio and USRP”, thesis MSc., University of Wollongong, Australia, 2013.

[19] J. Declerck et al., "SDR platform for $802.11 \mathrm{n}$ and 3-GPP LTE", International Conference on Embedded Computer Systems: Architectures, Modeling and Simulation, $\mathrm{S}$ a mo s, 2010, p p. $318-323$. https://doi.org/10.1109/ICSAMOS.2010.5 $\underline{642049}$.

[20] K. Aggrawal, M. Kamani and K. Vachhani, "Analysis of GSM air interface using DVB-T receiver and GNU radio", International Conference on Trends in Electronics and Informatics (ICEI), Tirunelveli, 2017, pp. $635-640$.

https://doi.org/10.1109/ICOEI.2017.8300 $\underline{780}$.

[21] C. D. R. Rodríguez, G. P. Leguizamón and C. S. Fajardo, "Processing threshold in an IEEE $802.11 \mathrm{a} / \mathrm{g} / \mathrm{p}$ receiver over GNU radio: A fuzzy logic application”, IEEE Symposium Series on Computational Intelligence (SSCI), Honolulu, HI, 2017 , p p. $1-8$. https://doi.org/10.1109/SSCI.2017.828536 $\underline{3}$.

[22] T. Juhana and S. Girianto, "An SDR-based multistation FM broadcasting monitoring system", 11th International Conference on Telecommunication Systems Services and Applications (TSSA), Lombok, 2017, pp. 1-4. https://doi.org/10.1109/TSSA.2017.82729 $\underline{43}$.

[23] J. J. H. Almeida, C. Akamine and P. B. Lopes, "A proposal for the next generation of ISDB-Tb using FBMC in a SDR implementation on GNU radio environment", 8th IEEE LatinAmerican Conference on Communications (LATINCOM), Medellin, 2016, pp. 1-6. https://doi.org/10.1109/TLA.2017.795934 o.
[24] R. Prieto, R. Rojas, I. Ladino and I. Díaz, "Experimental validation of a modulatordemodulator 16-CQAM using SDR", Congreso Internacional de Innovación y Tendencias en Ingeniería (CONIITI), B o g o tá, 2017 , p p . 1 - 6 . https://doi.org/10.1109/CONIITI.2017.82 $\underline{73321 .}$.

[25] Y. Shabara, A. Mohamed and A. K. Al-Ali, "A Hardware Implementation for Efficient Spectrum Access in Cognitive Radio Networks", IEEE Wireless Communications and Networking Conference (WCNC), San Francisco, CA, 2017 , p p. 1-6. https://doi.org/10.1109/WCNC.2017.7925 $\underline{442}$.

[26] L. Pedraza, C. Hernández, I. Páez and E. Rodríguez "Análisis de la Movilidad Espectral en Redes de Radio Cognitiva”, Inf. Tecnol., vol. 26, no. 6, 2015, pp.169-186. https://doi.org/10.4067/So718$\underline{07642015000600018 .}$.

[27] M. Jokinen, M. Sonkki and E. Salonen, "Phased Antenna Array Implementation with USRP”, IEEE Globecom Workshops (GC Wkshps), $\mathrm{S}$ i n g a p o r e, 2017 , p p . $1-5$. https://doi.org/10.1109/GLOCOMW.2017 .8269174 .

[28] Y. Cai, Z. Qin, F. Cui, G. Y. Li and J. A. McCann, "Modulation and Multiple Access for $5 \mathrm{G}$ Networks", IEEE Communications Surveys E Tutorials, vol. 20, no. 1, 2018, pp. 629-646. https://doi.org/10.1109/COMST.2017.276 $\underline{6698}$.

[29] H. Jebbar, S. E. Hassani and A. E. Abbassi, "Performance study of $5 \mathrm{G}$ multicarrier waveforms", International Conference on Wireless Networks and Mobile Communications (WINCOM), Rabat, 2017, pp. $1-6$. https://doi.org/10.1109/WINCOM.2017.8 238183. 
[30] Y. Hu, "An Improved Algorithm for PAPR Reduction in OFDM System", 4th International Conference on Wireless Communications, Networking and Mobile Computing, Dalian, 2008 , pp. 1-4. https://doi.org/10.1109/WiCom.2008.191.

[31] M. Paredes and M. Fernandez "The Problem of Peak-to-Average Power Ratio in OFDM Systems", 2015, pp. 1-7. [Online]. Available at: https://arxiv.org/pdf/1503.08271.pdf.

[32] A. Gangwar and M. Bhardwaj, "An Overview: Peak to Average Power Ratio in OFDM system \& its Effect", International Journal of Communication and Computer Technologies, vol. 1, no. 2, 2012, pp. 22-25.

[33] Z. E. Ankarall, A. ahin and H. Arslan, "Joint Time-Frequency Alignment for PAPR and OOBE Suppression of OFDM-Based Waveforms", IEEE Communications Letters, vol. 21, no. 12, 2017 , pp. $2586-2589$. https://doi.org/10.1109/LCOMM.2017.27 46082.

[34] V. Parmar and A. Christian, "A perlustration on out of band emission mitigation techniques in OFDM", International Conference on Communication and Signal Processing (ICCSP), Chennai, 2017, pp. 370$\begin{array}{lll}3 & 7 & 5\end{array}$ https://doi.org/10.1109/ICCSP.2017.8286380.

[35] W. Chen, G. Cui, J. Duan, W. Wang and Y. Zhang, "Research on utilizing guard band in LTE uplink co-existence based on uncoordinated deployment scenario", IET International Conference on Communication Technology and Application (ICCTA 2011), B e i jing, 2011 , p p. 44 1-446. https://doi.org/10.1049/cp.2011.0707.

[36] R. Ratasuk, J. Tan, N. Mangalvedhe, M. H. Ng and A. Ghosh, "Analysis of NB-IoT Deployment in LTE Guard-Band”, IEEE 85th Vehicular Technology Conference
(VTC Spring), Sydney, NSW, 2017, pp. 1-5. https://doi.org/10.1109/VTCSpring.2017. $\underline{8108184}$.

[37] M. Cheema and S. A. Kulkarni, "Iterative ICI Cancellation in MIMO OFDM WiMAX System with LDPC Channel Coding”, Proceedings - 2015 International Conference on Computational Intelligence and Communication Networks, CICN 2015, $2015, \quad$ p p. $532-536$. https://doi.org/10.1109/CICN.2015.109.

[38] S. Jacobsson, G. Durisi, M. Coldrey and C. Studer, "On out-of-band emissions of quantized precoding in massive MU-MIMOOFDM", 51st Asilomar Conference on Signals, Systems, and Computers, Pacific Grove, CA, USA, 2017 , pp. 21-26. https://doi.org/10.1109/ACSSC.2017.8335 $\underline{128}$.

[39] R. A. Gopinath and C. S. Burrus, "On upsampling, downsampling, and rational sampling rate filter banks", IEEE Transactions on Signal Processing, vol. 42, no. 4, 1994 , pp. 812-824. https://doi.org/10.1109/78.285645.

[40] S. C. Gupta, "Delta Function", IEEE Transactions on Education, vol. E-7, no. 1, 1964 , p p. $16-22$. https://doi.org/10.1109/TE.1964.4321835.

[41] D. Panaitopol, R. Datta and G. Fettweis, "Cyclostationary detection of cognitive radio systems using GFDM modulation", IEEE Wireless Communications and Networking Conference (WCNC), Shanghai, 2012, pp. $930-934$.

https://doi.org/10.1109/WCNC.2012.62 14508 .

[42] N. Michailow, I. Gaspar, S. Krone, M. Lentmaier and G. Fettweis, "Generalized frequency division multiplexing: Analysis of an alternative multi-carrier technique for next generation cellular systems", International Symposium on Wireless Communication Systems (ISWCS), Paris, 2012, pp. 171-175. 
https://

doi.org/10.1109/ISWCS.2012.6328352.

[43] G. R. Al-Juboori, A. Doufexi and A. R. Nix, "System level $5 \mathrm{G}$ evaluation of GFDM waveforms in an LTE-A platform", International Symposium on Wireless Communication Systems (ISWCS), Poznan, 2016, pp. 335-340.

https://doi.org/10.1109/ISWCS.2016.76009 $\underline{25}$.

[44] T. Wong and T. Lok, "Intersymbol interference and equalization”, 2018. [Online]. Available at:

http://wireless.ece.ufl.edu/twong/Notes/Co $\underline{\mathrm{mm} / \mathrm{ch} 4 . p d f}$.

[45] J. Demel, C. Bockelmann and A. Dekorsy. "An optimized GFDM software implementation for future Cloud-RAN and field tests", Proceedings of the 7 th GNU Radio Conference, 2017, pp. 1-8.

[46] Ettus Research WEB site, "USRP product line”, 2018. [Online]. Available at: https://www.ettus.com/product.

[47] Tyco Electronics, "SMA Connectors", 2018. [ $\mathrm{O}$ n $1 \mathrm{in} \mathrm{e}]$. A v a i l a b l e a t : http://www.te.com/commerce/DocumentD elivery/DDEController?Action $=$ showdoc $\&$ DocId=Catalog + Section\%7F 1307191_SMA _Connectors\%7F0307\%7Fpdf\%7FEnglish\% 7FENG_CS_1307191_SMA_Connectors_0 307.pdf\% 7 F 1053354-1.

[48] Anritsu, "WEB site of Anritsu", 2018. [O n l in e ]. Avail a ble a t : https://www.anritsu.com/en-US

[49] GNURadio, "WEB site of GNURadio", 2018. [Online]. Available at: https://gnuradio.org/about/

[50] ITU, "Emisiones no deseadas en el dominio fuera de banda, UIT-R SM.1541-6”, 2015. [Online]. Available a t:
https://www.itu.int/rec/R-REC$\underline{\text { SM.1541/es. }}$

[51] ITU, "Variación del límite entre los dominios de emisión fuera de banda y no esencial requerida para la aplicación de las Recomendaciones UIT-R SM.1541 y UIT-R SM.329, UIT-R SM.1539-1", 2015. [ $\mathrm{O}$ n l i n e ]. A v a i l a ble a t : https://www.itu.int/rec/R-RECSM.1539/es. 